\title{
Dongkrak Elektrik Dikontrol Melalui Smartphone Android
}

\author{
Lukas B. Setyawan', Gunawan Dewantoro ${ }^{2}$, Anggoro Agung Pambudi ${ }^{3}$ \\ Program Studi Teknik Elektro, \\ Fakultas Teknik Elektronika dan Komputer, \\ Universitas Kristen Satya Wacana, Salatiga \\ ${ }^{1}$ lukas.setyawan@staff.uksw.edu, ${ }^{2}$ gunawan.dewantoro@staff.uksw.edu, \\ 3agung.ynwa30@gmail.com
}

\begin{abstract}
Ringkasan
Sistem pengontrol dongkrak elektrik menggunakan smartphone android ini memanfaatkan koneksi bluetooth sebagai media komunikasi sehingga pengguna dapat mengontrol dongkrak dari kejauhan. Dongkrak elektrik mendapatkan tenaga dari power-outlet lighter mobil. Sistem ini dilengkapi dengan sensor jarak dan sensor logam untuk membaca jarak dan untuk mengetahui apakah dongkrak sudah mengenai rangka mobil atau belum. Aplikasi Android dijalankan pada platform Android 4.1 (kitkat). Dongkrak hanya dapat dikontrol oleh satu smartphone.
\end{abstract}

Kata kunci: dongkrak elektrik, smartphone android, bluetooth

\section{Pendahuluan}

Dongkrak sangat diperlukan pada saat mobil mengalami masalah, misalnya perlu mengganti ban karena kempes. Dongkrak konvensional memerlukan tenaga cukup besar untuk memutar stang dongkrak. Sistem dongkrak elektrik memanfaatkan motor penggerak untuk menaikkan dan menurunkan dongkrak sehingga memudahkan pengguna mengoperasikan dongkrak. Agar bisa dikontrol dari kejauhan maka digunakan smartphone Android memanfaatkan koneksi bluetooth yang dimiliki smartphone. Pengontrolan dongkrak elektrik dilakukan pengguna melalui tampilan layar sentuh smartphone android. Proses pengontrolan dilakukan oleh pogram aplikasi yang ditanam di dalam smartphone.

Pembahasan dimulai dengan penjelasan sistem dongkrak elektrik meliputi proses kerja sistem, sistem mekanik, sistem perangkat keras, dan sistem perangkat lunak. Kemudian dilanjutkan dengan hasil pengujian dan diakhiri dengan kesimpulan.

\section{Sistem Dongkrak Elektrik}

Sistem dongkrak elektrik ini terdiri dari dua bagian. Bagian utama adalah dongkrak yang telah dilengkapi dengan motor penggerak, modul pengukur jarak, modul bluetooth, serta modul mikrokontroler. Bagian kedua adalah smartphone android yang berisi program aplikasi untuk melakukan pengontrolan dongkrak elektrik. Bagian utama dihubungkan ke sumber tegangan melalui power-outlet lighter mobil. Sebagai motor penggerak digunakan motor DC yang dilengkapi dengan gearbox agar diperoleh torsi 
yang cukup besar untuk memutar dongkrak. Dongkrak yang digunakan memiliki daya angkat sebesar 1,2 ton. Modul pengukur jarak menggunakan sensor ultrasonik SRF-04 yang digunakan untuk mengukur ketinggian dongkrak. Modul bluetooth HC-05 digunakan sebagai media komunikasi antara mikrokontroler dan smartphone. Pengendali utama digunakan mikrokontroler AT-Mega 328 untuk mengatur proses kerja sistem dongkrak elektrik. Mikrokontroler ini bekerja berdasarkan perintah yang dikirimkan oleh smartphone dan berkomunikasi lewat media bluetooth. Pengguna mengatur dongkrak elektrik melalui penekanan layar sentuh pada smartphone dengan menjalankan program aplikasi. Konfigurasi sistem dongkrak elektrik diperlihatkan oleh Gambar 1. Contoh tampilan layar smartphone ditunjukkan oleh Gambar 2.

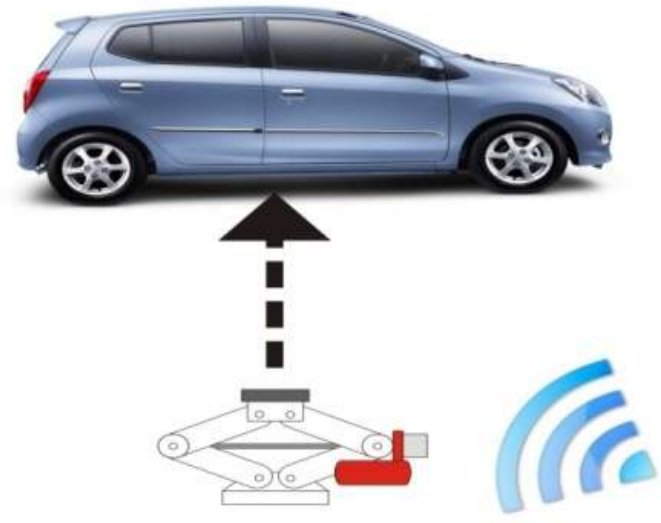

Gambar 1. Konfigurasi sistem dongkrak elektrik

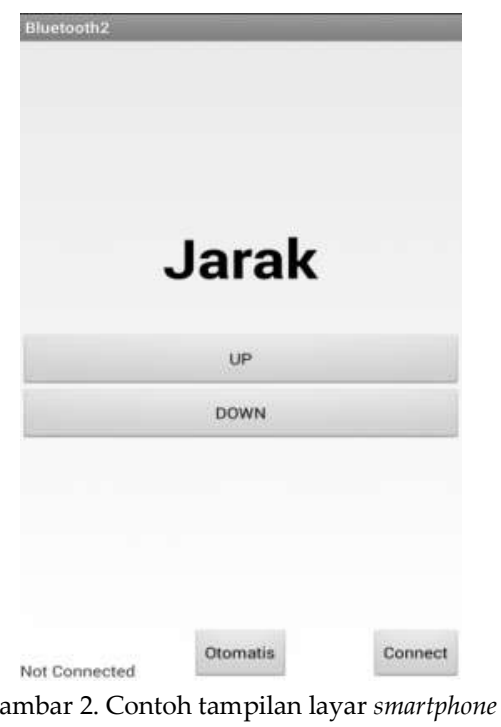

\subsection{Proses Kerja Sistem}

Bagan kotak sistem dongkrak elektrik diperlihatkan pada Gambar 3. Pada saat mulai menggunakan dongkrak elektrik, pengguna meletakkan dongkrak di bawah kerangka mobil yang akan didongkrak. Kemudian dongkrak elektrik dihubungkan ke sumber 
tegangan melalui power-outlet lighter mobil. Selanjutnya pengguna menjalankan program aplikasi di smartphone. Berikutnya pengguna menghubungkan smartphone ke jaringan bluetooth dongkrak elektrik dengan cara menekan tombol pada layar sentuh smartphone. Setelah terhubung maka dongkrak siap digunakan. Pada tampilan aplikasi smartphone tersedia tombol UP dan DOWN untuk memerintahkan arah gerakan dongkrak ke atas atau ke bawah. Pada layar tampilan bisa dibaca selisih ketinggian dongkrak dari awal dongkrak mulai bergerak sampai dongkrak berhenti bergerak. Bagan kotak sistem diperlihatkan oleh Gambar 3.

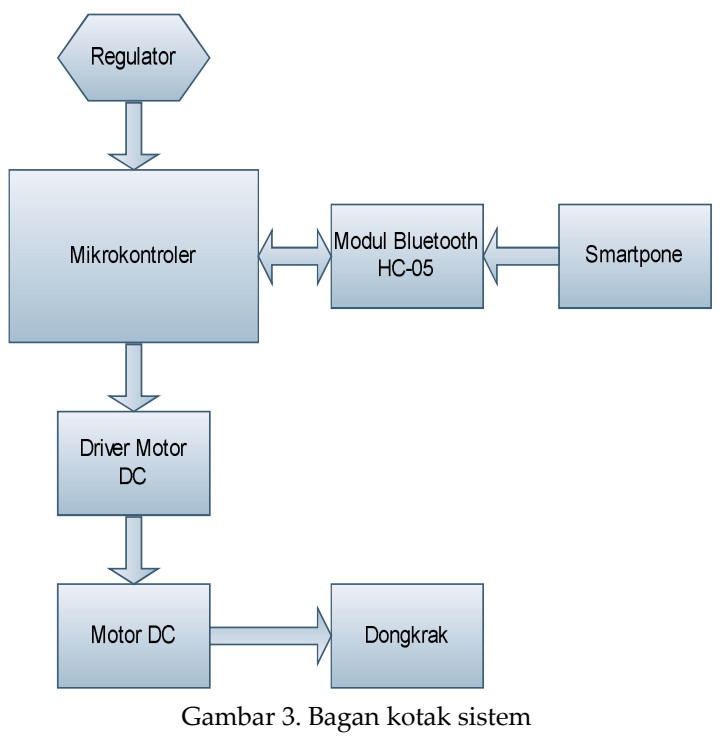

\subsection{Sistem Mekanik}

Sistem mekanik dongkrak elektrik tersusun dari dongkrak, motor DC, gear box, sensor ultrasonik SRF-04, sensor proximity, modul bluetooth, dan mikrokontroler AT-Mega 328. Sketsa sistem mekanik ditunjukkan oleh Gambar 4. Pemasangan motor DC dan gear box diperlihatkan pada Gambar 5. Keseluruhan dongkrak dapat dilihat pada Gambar 6.

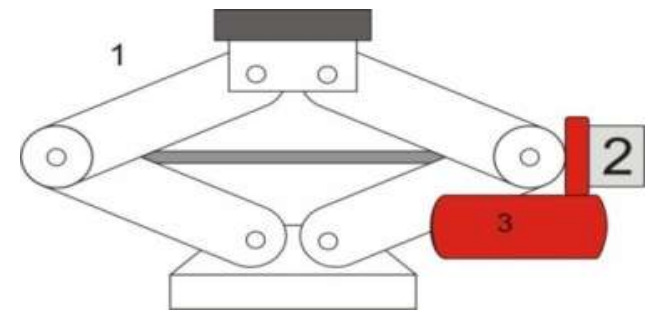

Gambar 4. Sketsa mekanik dongkrak: 1. Dongkrak; 2. Modul mikrokontroler dan modul bluetooth; 3. Motor DC dan gear box 


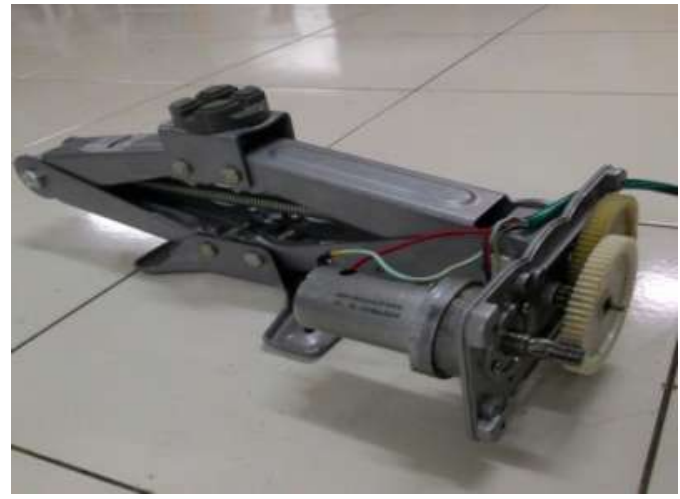

Gambar 5. Gambar pemasangan motor DC dan gear box pada dongkrak

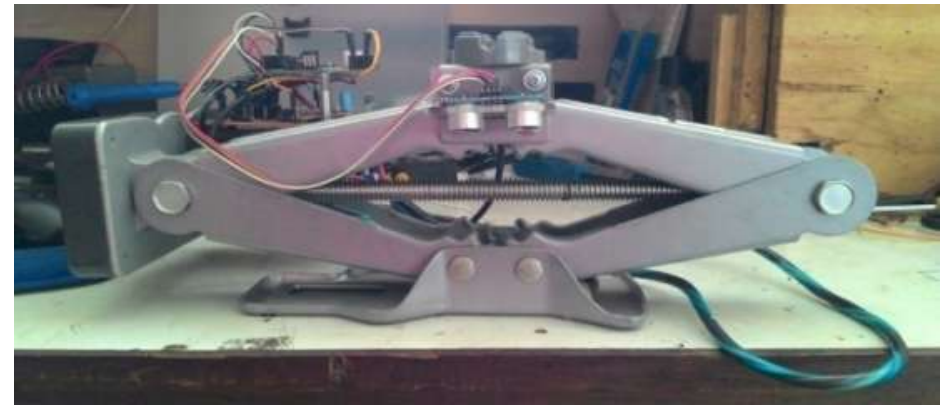

Gambar 6. Gambar realisasi dongkrak

\subsection{Sistem Perangkat Keras}

Perangkat keras terdiri atas mikrokontroler AT-Mega 328, modul bluetooth HC-05, sensor ultrasonik SRF-04, dan sensor proximity. Mikrokontroler AT-Mega 328 berfungsi untuk mengatur proses kerja sistem. Sensor ultrasonik SRF-04 digunakan untuk mengukur jarak. Sensor proximity dipakai untuk mengetahui apakah dongkrak sudah menyentuh dasar kerangka mobil atau belum. Modul bluetooth HC-05 digunakan sebagai media komunikasi antara mikrokontroler dan smartphone.

Skema sistem minimum AT-Mega 328 dapat dilihat pada Gambar 7. Tabel 1 menunjukkan koneksi mikrokontroler dengan sensor dan untai saklar. Skema modul bluetooth ditunjukkan oleh Gambar 8. Skema untai saklar diperlihatkan pada Gambar 9.

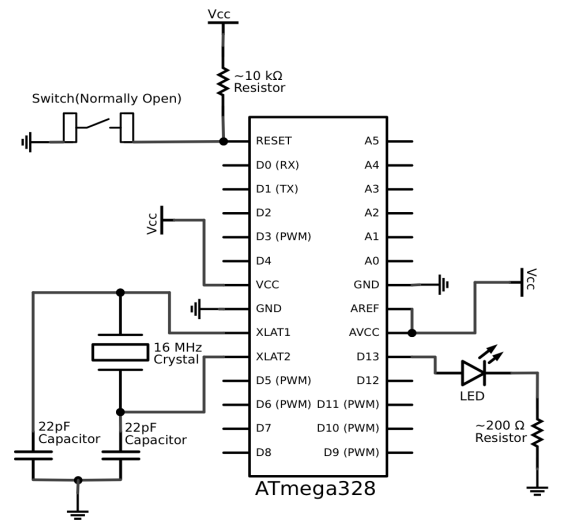

Gambar 7. Skema sistem minimum AT-Mega 328 
Dongkrak Elektrik Dikontrol Melalui Smartphone Android Lukas B. Setyawan, Gunawan Dewantoro, Anggoro Agung Pambudi

Tabel 1. Tabel koneksi port mikrokontroler

\begin{tabular}{|c|c|}
\hline PORT & KONEKSI \\
\hline PORT B. 2 & Echo SRF \\
\hline PORT B.3 & Trigger SRF \\
\hline PORT D. 0 & RX Bluetooth \\
\hline PORT D.1 & TX Bluetooth \\
\hline PORT D. 2 & Untai \\
\hline PORT D.4 & Untai \\
\hline
\end{tabular}

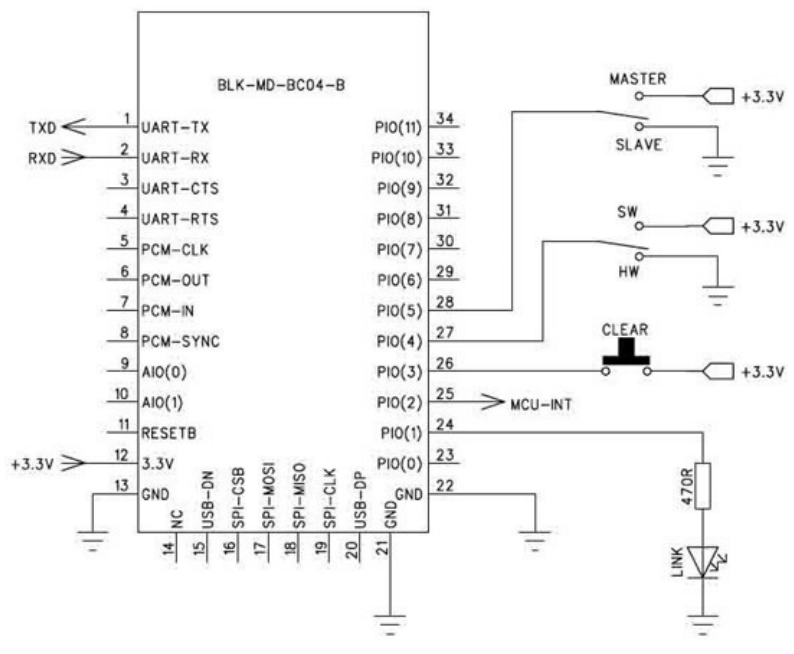

Gambar 8. Skema modul bluetooth HC-05

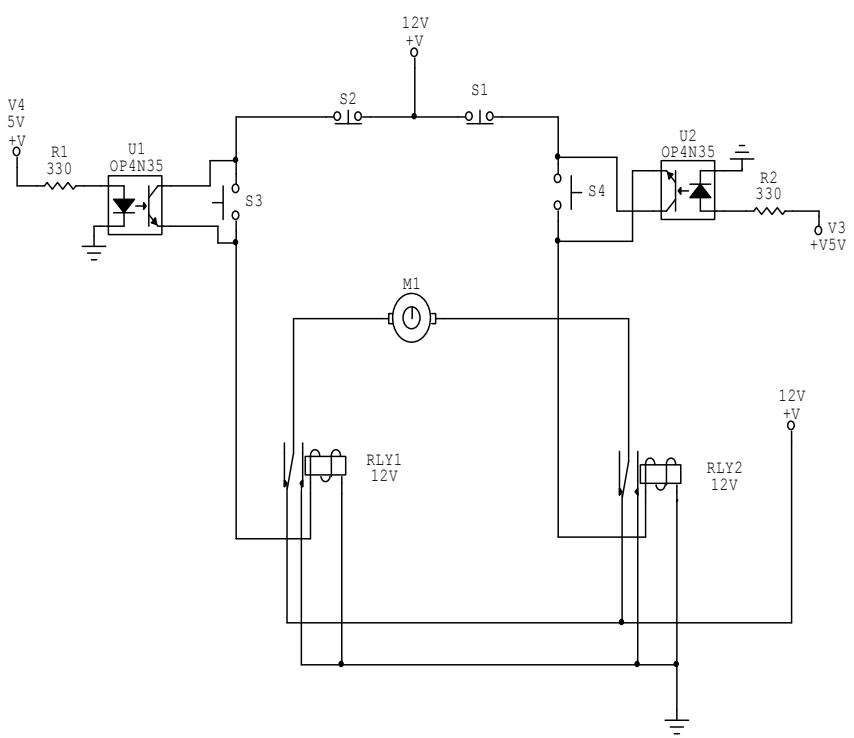

Gambar 9. Skema Untai Saklar

\subsection{Sistem Perangkat Lunak}

Perangkat lunak ditanam di smartphone android dalam bentuk program aplikasi yang berfungsi untuk melakukan interaksi antara sistem dan pengguna. Bagan alir perangkat lunak ditunjukkan oleh Gambar 10. 


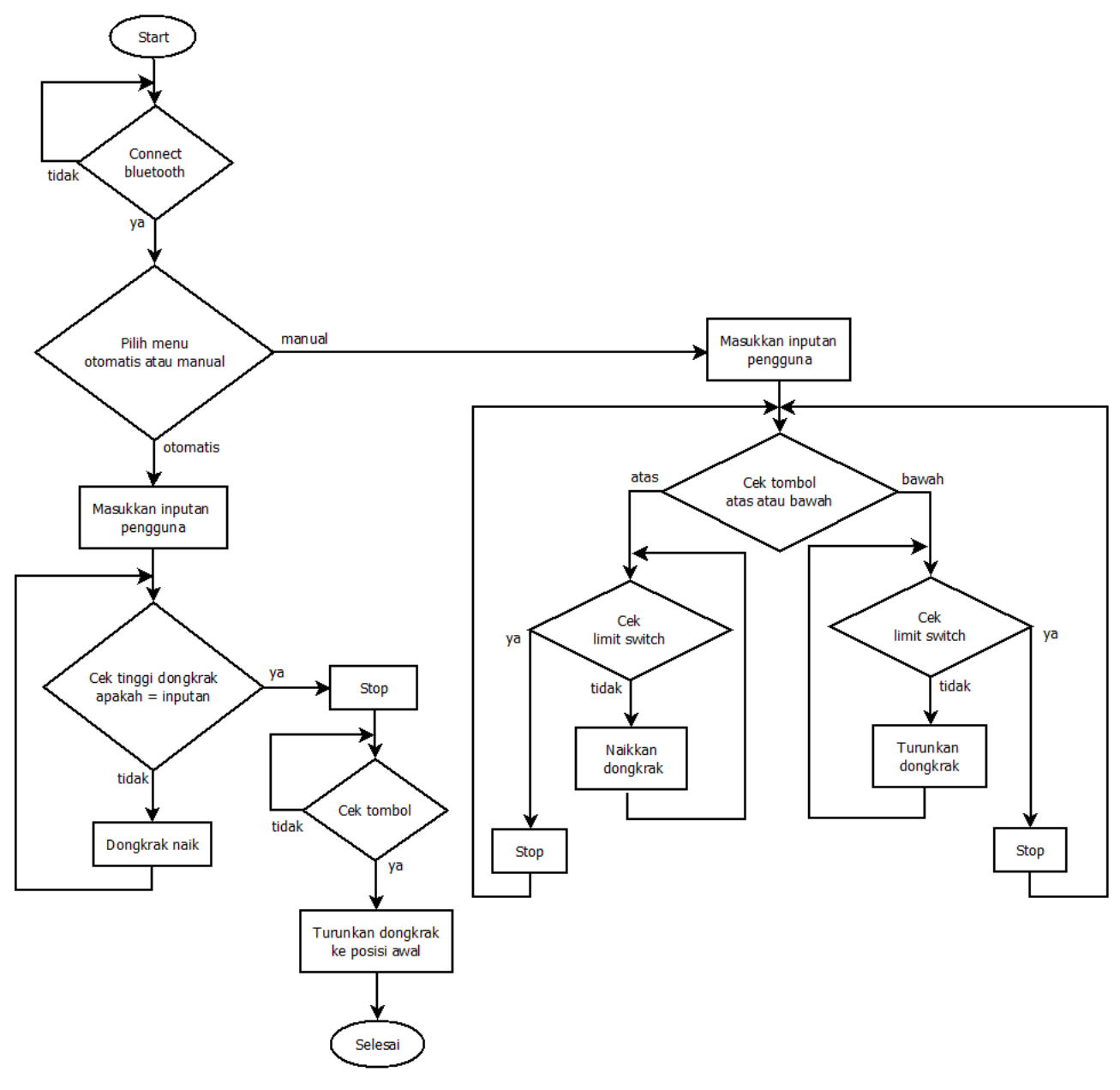

Gambar 10. Bagan alir Perangkat Lunak

\section{Hasil Pengujian}

Pengujian sistem dongkrak elektrik dilakukan untuk mengontrol dongkrak pada mobil Daihatsu Hi Jet 1000 dengan bobot mobil sekitar 1 ton. Program aplikasi ditanam pada smartphone Android dengan platform Android 4.1 (Kitkat). Pengujian sistem menunjukkan bahwa program aplikasi berhasil diimplementasikan menggunakan perangkat smartphone Asus Zenfone 5 (4.4.2), Oppo 831 R (4.3.3), dan Mito A77 (4.1.1). 


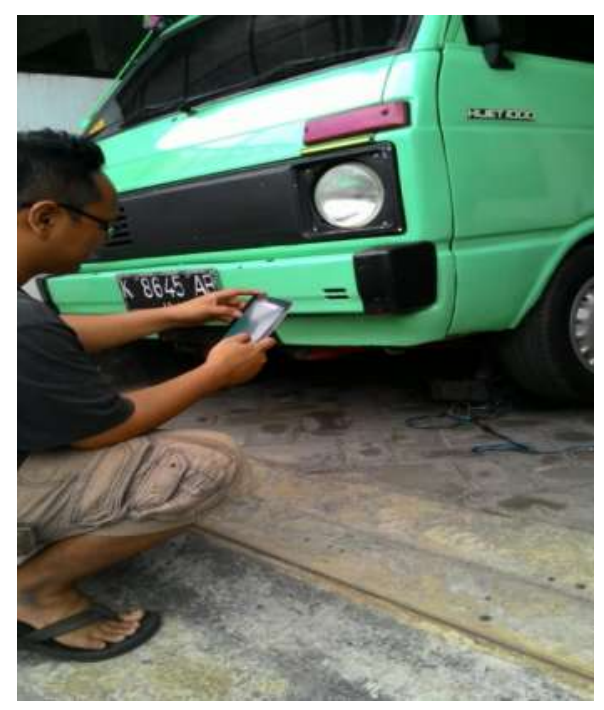

Gambar 11. Pengujian kontrol dongkrak

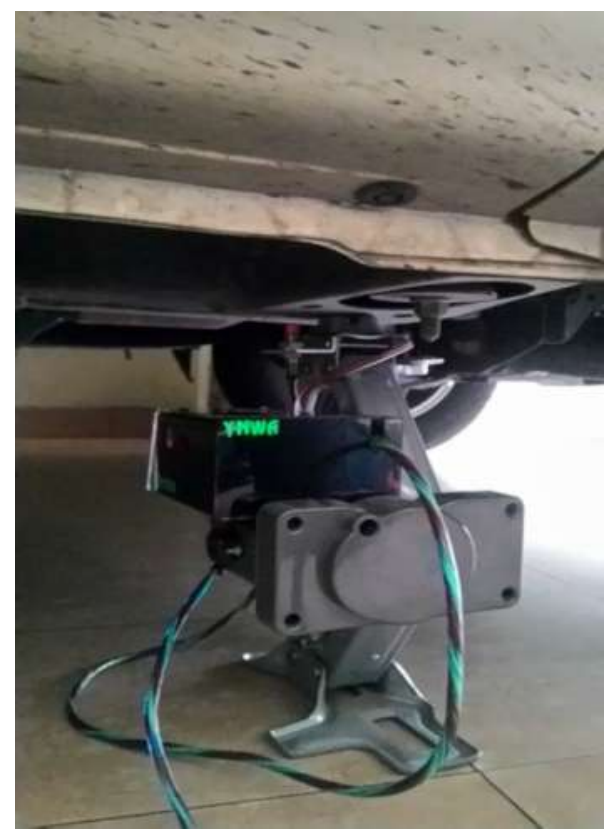

Gambar 12. Peletakan dongkrak pada mobil 


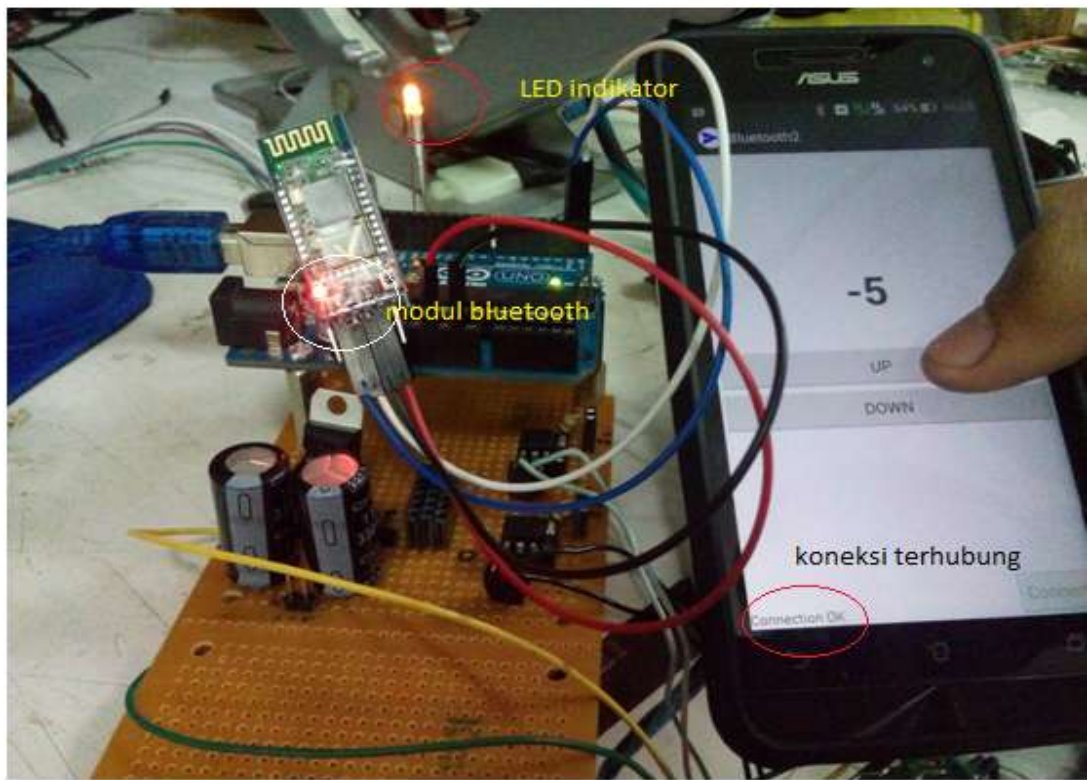

Gambar 13. Pengujian sinkronisasi bluetooth dan smartphone

\section{Kesimpulan}

Sistem pengontrol dongkrak elektrik telah berhasil direalisasikan menggunakan perangkat smartphone Asus Zenfone 5 (4.4.2), Oppo 831 R (4.3.3), dan Mito A77 (4.1.1). Sistem hanya dapat dikontrol dengan satu smartphone. Dongkrak dapat bekerja sesuai fungsinya yaitu menaikkan dan menurunkan mobil dengan berat \pm 1 ton melalui kontrol smartphone. Aplikasi dapat di-install pada smartphone Android dengan platform 4.1 (kitkat).

\section{Daftar Pustaka}

[1] ATMEL,"Datasheet Atmega 328", [online], www.atmel.com, diakses tanggal 26 Desember 2014.

[2] HC Bluetooth Product, "Datasheet HC-05", [online], www.rcscomponents.kiev.ua/datasheets/hc_hc-05/, diakses tanggal 27 Maret 2015. 